\title{
Prevalence of Bacterial Vaginitis in Women with Recurrent Abortion in Comparison with Normal Pregnant Women
}

\author{
Samira Sherzad Hussien ${ }^{1}$, Shahlaa Abd-Alrahman Mohammed ${ }^{2}$, Bushra Mohammed Salih ${ }^{3}$ \\ ${ }^{I}$ M.B.Ch.B, H.D.O.G, Kirkuk Health Directorate, Kirkuk, Iraq, ${ }^{2}$ M.B.Ch.B, H.D.O.G, Kirkuk Health Directorate, \\ Kirkuk, Iraq, ${ }^{3}$ M.B.Ch.B, H.D.O.G, Tikrit Health Directorate, Tikrit, Iraq
}

\begin{abstract}
Across-sectional study was done on a total of 80 deep vaginal swabs (40 women with recurrent abortion and 40 pregnant women as control group) were collected from the September 2019 to the end of November 2019 from inpatients and outpatients women attended to Kirkuk general hospital to evaluate the prevalence of vaginitis due to bacterial causes and its relation with abortion in pregnant women. vaginal swabs were inoculated in bacterial media whose were prepared and sterilized according to the manufacturer's instruction. The prepared media were used for isolation, determination of the viable count, identification and susceptibility testing these media were carried out after being solidified. Swabs was inoculated onto MacConkey, nutrient and blood agars. Then the inoculated plates were incubated at $37^{\circ} \mathrm{C}$ for $24 \mathrm{hr}$. The included 40 women with recurrent miscarriage with age range (20-44 years), the study showed that 12 of 40 were within the age group 30-39 years and 12 were below 30 years with mean age (31.6 years) and their husbands mean age (35.43 years) and $65 \%$ of cases were rural. There was $60 \%$ of cases were with history of 3 miscarriage and $18.75 \%$ were 4 miscarriage. The study also revealed that majority of cases were parity 3-6. The study also indicated that majority of cases have history of miscarriage in the $1^{\text {st }}$ trimester in pregnancy. The study demonstrated that $55 \%$ of women with recurrent abortion have positive HVS culture comparing with $48 \%$ of pregnant women (control group). The study showed that $77.27 \%$ of women had aborted in the $1^{\text {st }}$ trimester of pregnancy and the lowest rate of abortion $3 \%$ was in the $3^{\text {rd }}$ trimester. The study revealed that highest rate of isolated bacteria from the HVS culture of aborted women was Gardenellavaginalis (36.36\%), E. coli $(27.27 \%)$ S. aureus $(22.73 \%)$ and the higher rates of isolated bacteria from pregnant women were $50 \% \%$ for $E$ coli.
\end{abstract}

Keywords: Bacterial vaginitis; Gardnellavaginosis; Recurrent abortion; Pregnancy.

\section{Introduction}

Vaginitis is the mostcommongynecologicalinfection among women of fertile age ${ }^{(1)}$. Bacterial vaginosis (BV) comprises the $50 \%$ of the all cases of vaginitis ${ }^{(2)}$. To understand the pathological events related to vaginitis, it is necessary to understand the normal vaginal flora. In normal vaginal flora, there are Lactobacillus species in $95 \%$ and facultative anaerobic and anaerobic microorganisms, including: Gardnerellavaginalis, Staphylococcus epidermis, Mycoplasma hominis, Streptococcal species, Bacterioides species, Prevotellabivius, Peptostreptococci species, in 5\%(3). In most cases of BV, the predominant microbe is the facultative anaerobe Gardnerellavaginalis. However, evidence from recent studies of the pathogenesis of
BV suggests that this bacterium forms a biofilm in the vaginal epithelium that serves as a "scaffolding" to which other bacterial species adhere in a symbiotic fashion, colonizing the vagina ${ }^{(4)}$. Though asymptomatic in at least half of affected women, thispolymicrobial condition can produce a thin, white, homogenous discharge with a distinct "fishy" odor ${ }^{(5)}$. The changes in the vaginal flora seen in BV are associated with serious sequelae, such as preterm delivery, spontaneous abortion, postpartum endometritis, and increased susceptibility to HIV and other sexually transmitted infections ${ }^{(6,7)}$. The aim of this study was to evaluate the prevalence of vaginitis due to bacterial causes and its relation with abortion in pregnant women. 


\section{Materials and Method}

Across-sectional study was done on a total of 80 deep vaginal swabs (40 women with recurrent abortion and 40 pregnant women as control group) were collected from the September 2019 to the end of November 2019 from inpatients and outpatients women attended to Kirkuk general hospital. Collection of vaginal swabs included:

1. The swab package was partially opened.

2. Carefully the swab was inserted into vagina about 2 inches $(5 \mathrm{~cm})$ past the introitus and gently rotated for 10 to 30 seconds.

3. When the swab touched the vagina walls and moisture and absorbed the moisture, it was withdrawn without touching the skin.

4. Swabs was delivered to the laboratory within 1 hour of collection.

5. The swabs samples were cultured in blood agar and MacConkey agar for 24 hour $^{(8)}$.

Media were prepared and sterilized according to the manufacturer's instruction. The prepared media were used for isolation, determination of the viable count, identification and susceptibility testing these media were carried out after being solidified. Swabs was inoculated onto MacConkey, nutrient and blood agars. Then the inoculated plates were incubated at $37^{\circ} \mathrm{C}$ for $24 \mathrm{hr}$.

\section{Results}

The included 40 women with recurrent miscarriage with age range (20-44 years), the study showed that 12 of 40 were within the age group 30-39 years and 12 were below 30 years with mean age (31.6 years) and their husbands mean age ( 35.43 years) and $65 \%$ of cases were rural. There was $60 \%$ of cases were with history of 3 miscarriage and $18.75 \%$ were 4 miscarriage . The study also revealed that majority of cases were parity $3-6$. The study also indicated that majority of cases have history of miscarriage in the $1^{\text {st }}$ trimester in pregnancy, Table 1.

Table 1: General characteristics of women with recurrent miscarriage

\begin{tabular}{|l|c|}
\hline Characteristics & Aborted women (n:40) \\
\hline$<30$ years & 12 \\
\hline $30-39$ & 12 \\
\hline$\geq 40$ & 6 \\
\hline Mean (year) & 31.6 \\
\hline Mean age of husbands & 35.43 \\
\hline Rural & 26 \\
\hline Urban & 14 \\
\hline Miscarriage No. & \\
\hline 3 & 20 \\
\hline 4 & 10 \\
\hline 5 and more & 10 \\
\hline Parity & \\
\hline None & 7 \\
\hline $1-2$ & 14 \\
\hline $3-4$ & 21 \\
\hline $5-6$ & 23 \\
\hline$>6$ & 15 \\
\hline
\end{tabular}

The study demonstrated that $55 \%$ of women with recurrent abortion have positive HVS culture comparing with $48 \%$ of pregnant women (control group), Table 2.

Table 2: Distribution of HVS culture in recurrent aborted women and the control group.

\begin{tabular}{|l|c|c|c|c|}
\hline \multirow{2}{*}{ Results of vaginal swab culture } & \multicolumn{4}{|c|}{ Study Groups } \\
\cline { 2 - 5 } & Recurrent Abortion Women & \multicolumn{2}{|c|}{ Pregnant Women (Control) } \\
\cline { 2 - 5 } & No. & 55 & \multicolumn{2}{c|}{ No. } \\
\hline Pathogenic bacteria & 22 & 45 & 10 & 25 \\
\hline No bacterial infection & 12 & 30 & 75 \\
\hline
\end{tabular}

P. value $<0.01$

The study showed that $77.27 \%$ of women had aborted in the $1^{\text {st }}$ trimester of pregnancy and the lowest rate of abortion $3 \%$ was in the $3^{\text {rd }}$ trimester, Table 3 . 
Table 3: Distribution of aborted women with HVS positive according to Trimester of abortion

\begin{tabular}{|l|c|c|}
\hline Trimester of abortion & No. & \% \\
\hline $1^{\text {st }}$ trimester & 17 & 77.27 \\
\hline $2^{\text {nd }}$ trimester & 4 & 18.18 \\
\hline $3^{\text {rd }}$ trimester & 1 & 4.55 \\
\hline Total & $\mathbf{2 2}$ & $\mathbf{1 0 0}$ \\
\hline
\end{tabular}

Figure 1 shows that the highest rate of aborted women have suffer from abortion twice number during their marriage life.

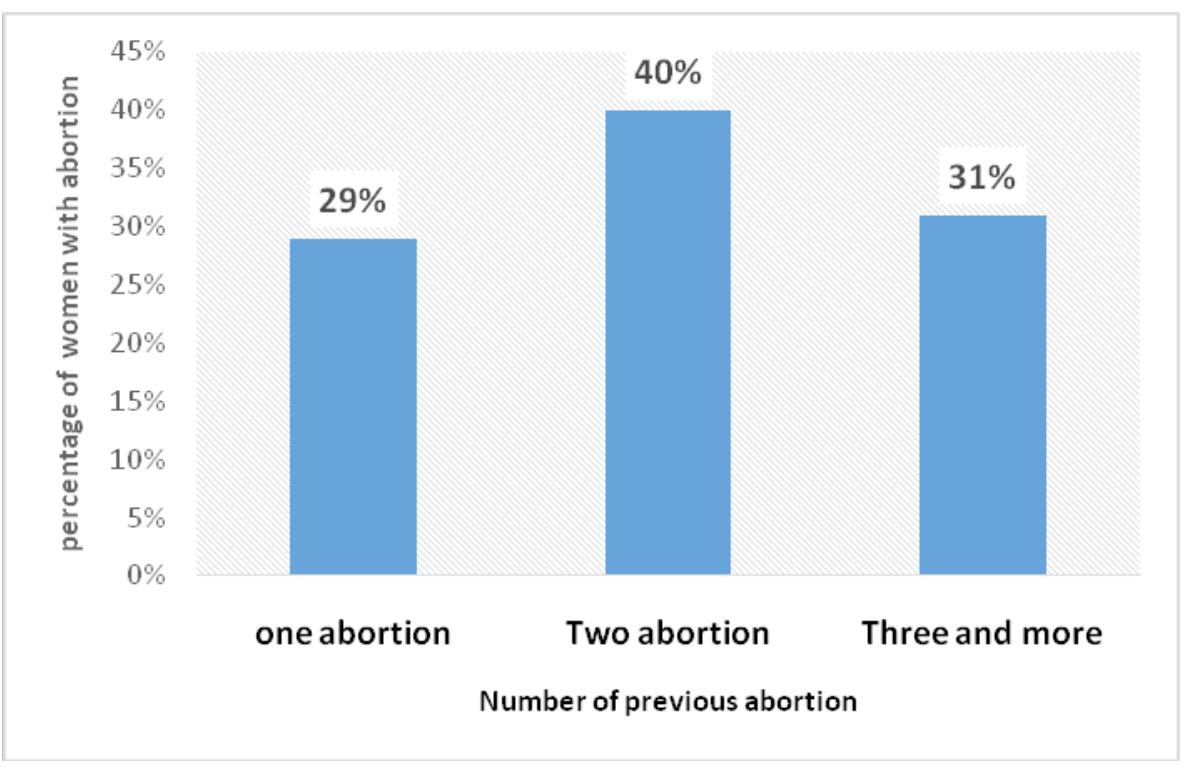

Figure 1: Distribution of aborted women according to number of abortions.

The study revealed that highest rate of isolated bacteria from the HVS culture of aborted women was Gardenellavaginalis $(36.36 \%)$, E. coli $(27.27 \%)$ S. aureus $(22.73 \%)$ and the higher rates of isolated bacteria from pregnant women were $50 \% \%$ for $E$ coli, Table 4 .

Table 4: Distribution of isolated pathogenic bacteria among study groups.

\begin{tabular}{|l|c|c|c|c|}
\hline \multirow{2}{*}{ Isolated bacteria } & \multicolumn{2}{|c|}{ Aborted women } & \multicolumn{2}{c|}{ Control women } \\
\cline { 2 - 5 } & No & \% & No & \% \\
\hline Gardenellavaginalis & 8 & 36.36 & 1 & 8.33 \\
\hline Staphylococcus aureus & 5 & 22.73 & 3 & 25 \\
\hline E. coli & 6 & 27.27 & 6 & 50 \\
\hline Klebsiellaspp & 3 & 13.64 & 2 & 16.67 \\
\hline Total & 22 & 100 & 12 & 100 \\
\hline
\end{tabular}

\section{Discussion}

In agreement with these finding, Sundari et al ${ }^{(9)}$ reported in their study that the majority of the sample was reported at first trimester of pregnancy. This result is in agreement with the study of Hassan et al ${ }^{(10)}$ and Ali ${ }^{(11)}$ who reported a similar results. Al-dorri ${ }^{(12)}$ found in a study that aborted pregnant women with Listeria infection most common in $1^{\text {st }}$ trimester $(<12 \mathrm{wk})$ was $54(60.68 \%)$ and at late (12-20 wk) was 35(39.32\%). Jamshidi et 
$a l{ }^{(13)}$ who reported pregnant women with abortion at gestational age of early $(<12 \mathrm{wk})$ was $54(60.68 \%)$ and at late (12-20 wk) was $35(39.32 \%)$. Ra'ad et al ${ }^{(14)}$ in a study of vaginitis in married women in Tikrit city found that women with $1^{\text {st }}$ trimester of abortion recorded the highest rate of abortion. In present study, the overall prevalence of vaginal infections (57\%) was coherent with several studies done earlier. A study done in Kirkuk found that $33.2 \%$ of women with recurrent abortion have positive HVS culture ${ }^{(15)}$. Chambers ${ }^{(16)}$ displayed that $34.7 \%$ of women in India had positive HVS culture. Go VF et al ${ }^{(17)}$ revealed that, the prevalence of vaginal infection in Vietnam was $49.5 \%$. Bahram et al ${ }^{(18)}$ found that HVS were positive in $27.6 \%$ Iranian women. This variation might be methodology difference in isolation and identification of etiologies of vaginal infections. Moreover, environmental factors and difference on the actual study participants might also explain the above discrepancy. Manges et $a l^{(19)}$ demonstrated that the most prevalent $G$. vaginosis bacteria were was with rate (45.61\%). The study was inconsistence with a study done in Erbil by Mohammed ${ }^{(20)}$ who found a high percentage (46.21\%) of $E$ coli in his study. This may be due to the differences of the sites of swabs being taken from the hospital as a whole in Erbil or may be explained by the level of health awareness of both, patients and health staff in different communities ${ }^{(21)}$. Hayat et $a l^{(22)}$ and) found that causative organisms of vaginitis were $E$. coli in less than one-third of cases followed by Klebsilla less than one quarter and more than 5\% were Proteus. Other studies denoted that $G$. vaginosis and $S$. aureusmay just be organisms causing local vaginal infection as they did not occur in the endocervix and may not have been responsible for the ascending upper genital tract infection in septic abortions. The result of the current study was supported by several studies done earlier. Carlson et $a l^{(23)}$ and Yong et $a l^{(24)}$ presented that women who suffer from spontaneous abortion are in $1^{\text {st }}$ trimester and $2^{\text {nd }}$ trimester while some of the women were multigravida had previous stillbirth, preterm birth, multiple birth, and previous miscarriage.

\section{Conclusion:}

Bacterial vaginosis was common in aborted women and $S$. aureus was the most isolated species followed by G. Vaginosisand E. coli.

Financial Disclosure: There is no financial disclosure.
Conflict of Interest: None to declare.

Ethical Clearance: All experimental protocols were approved under the Kirkuk Health Directorate and all experiments were carried out in accordance with approved guidelines.

\section{References}

1. Li YH, Marren A. Recurrent pregnancy loss. Australian J General Pract 2018;47(7):432-436.

2. Quaas AM. Infertility and Recurrent Pregnancy Loss. Glass’ Office Gynecology. 2014:205-233.

3. Bashiri A, Harlev A, Agarwal A. Recurrent pregnancy loss. Evidence-based evaluation, diagnosis and treatment. Switzerland: Springer International Publishing. 2016.

4. Işik G, Demirezen Ş, Dönmez HG, Beksaç MS. Bacterial vaginosis in association with spontaneous abortion and recurrent pregnancy losses. I Cytol/ IndAcad Cytologists 2016;33(3):135.

5. Cicinelli E, Matteo M, Tinelli R, et al. Chronic endometritis due to common bacteria is prevalent in women with recurrent miscarriage as confirmed by improved pregnancy outcome after antibiotic treatment. ReprodSci 2014;21(5):640-647.

6. Basu J, Agamasu E, Bendek B, Salafia C, Mishra A, Benfield N, Prasad P, Mikhail M. 736: Placental tumor necrosis factor- $\alpha$ levels throughout gestation in normal pregnancy. Am JObstetGynecol 2015;212(1): 359-360.

7. Azizieh FY, Raghupathy RG. Tumor necrosis factor- $\alpha$ and pregnancy complications: a prospective study. Med PrinPract 2015;24(2):165-170.

8. Holcberg G, Huleihel M, Sapir O, Katz M, Tsadkin M, Furman B, Mazor M, Myatt L. Increased production of tumor necrosis factor- $\alpha$ TNF- $\alpha$ by IUGR human placentae. European Journal of Obstetrics \& Gynecology and Reproductive Biology. 2001 Jan 1;94(1):69-72.

9. Shan D, Bai Y, Chen QH, Wu YX, Chen Q, Hu YY. Hyperthyroid heart disease in pregnancy: Retrospective analysis of a case series and review of the literature. World Journal of Clinical Cases. 2019 Oct 6;7(19):2953.

10. Hassan MA, Killick SR. Is previous aberrant reproductive outcome predictive of subsequently reduced fecundity?. Human reproduct 2005; 20(3):657-664. 
11- Ali IH. Effect of toxoplasmosis as a cause of abortion in pregnant women. Tikrit $\mathrm{J}$ Pure Sc 2009;14(2):202-208.

12. Al-dorri AZ. Study of bacteria Listeria monocytogenes in spontaneous aborted women in Salah Al-deen province. Tikrit J Pure Sc 2016;21(3).

13. Jamshidi M, Jahromi AS, Davoodian P, Amirian M, Zangeneh M, Jadcareh F. Seropositivity for Listeria monocytogenesin women with spontaneous abortion: a case-control study in Iran. Taiwanese J ObstetGynecol 2009;48(1):46-48.

14. Ra'ad AZ, Ahmed TH, Najim WS. Diagnosis of vaginitis in married women by microbiogical and molecular method in Tikrit City. Tikrit Med J 2015;20(1).

15. Kadir MA, Sulymaz MA, Dawood IS, ShamsEldin S. Trichomonasvaginalis and associated microorganisms in women with vaginal discharge in Kerkuk-Iraq. Ankara Med J. 2014;14(3):91-99.

16. Gupta G, Nandwam S, Agarwal A. Prevalence of candidiasis, trichomoniasis and bacterial vaginosis among women of reproductive age group. Indian $\mathbf{J}$ Pub Heal Res Dev. 2013;4(2):94-98.

17. Go VF, Quan VM, Celentano DD, Moulton LH, Zenilman JM. Prevalence and risk factors for reproductive tract infections among women in rural vietnam. Southeast Asian J Trop Med Pub Heal 2006;37:185-189.
18. Bahram A, Hamid B, Zohre T. Prevalence of bacterial vaginosis and impact of genital hygiene practices in non-pregnant women in Zanjan, Iran. Oman Med J. 2009;24:288-293.

19. Manges AR, Johnson JR, Foxman B, O'bryan TT, Fullerton KE, Riley LW. Widespread distribution of urinary tract infections caused by a multidrugresistant Escherichia coli clonal group. New England J Med 2001;345(14):1007-1013.

20. Muhammed S A. A bacteriological study on the incidence urinary tract infection in Rizgari Teaching Hospital in Erbil City 2002; Msc. thesis, college of science, Univ. of Salahaddin.

21. Delzell, JE, and Lefevre, ML. Urinary tract infection during pregnancy. Am. Acad family physicians 2000; 35(3), 40-66.

22. Hayat IM, Nagat SS, Nermine N, Zeinab AB. Prevalence of Vaginal Infection and Associated Risk Health Behaviors Among Married Women in Ismailia City. Int. J. Curr Microbiol App Sci 2015;4(5):555-567.

23. Carlson E, Mourgova M. Demographic consequences of social inequality in pregnancy outcomes. Genus 2003:11-28.

24. Yong C, Wang F, Famine F. Social Disruption, and Miscarriage: Evidence from Chinese Survey Dat, Center for Studies in Demography and Ecology (CSDE) Working Paper,2006. 